\title{
How Situation Affects Risk Taking Behavior
}

\author{
Dr. Yanuar Dananjaya BSc, MM
}

Universitas Pelita harapan Surabaya

\section{Abstract}

This paper examines how situation affects risk taking behavior. Two theories predict different outcomes on the effect of situation to risk taking. House Money Effect predicts that positive situation will result in increased risk taking due to availability of slack that can be risked. On the other hand, negative situation will decrease risk taking because of reduced slack. Thus House Money Effect describes positive relation between situation and risk taking behavior. On the contrary according to Reflection Effect from Prospect Theory, human beings are risk averse in gain situation but risk seeking in loss situation. Reflection Effect thus predicts that positive situation will result in decreased risk taking while negative situation will result in increased risk taking, in other word negative relation between situation and risk taking. To test which theory better describes the relation between situation and risk taking behavior, we examine how company performance affects risk taking behavior of the top management. Company performance is proxied using Return of Asset. Risk taking behavior is proxied using change of debt level. The result shows negative relation between situation and risk taking, and thus support Reflection Effect in Prospect Theory.

Keywords: Risk Taking, Risk Aversion, Prospect Theory, House Money Effect, Behavioral Finance.

\section{Introduction}

Is someone's risk preference, and thus his/her risk taking behavior, innate or it is can be influenced by external factors? If it is influenced by external factors, how those factors affect risk taking behavior? This matter is important to be determined because various finance theories make assumption that human risk preference is fix and always has characteristic of risk aversion. For example Capital Asset Pricing Model (CAPM), the main model used to calculate a stock expected return and thus cost of equity and cost of capital, assumes fix risk aversion in human being. In CAPM a stock expected return depends on beta, the measurement of its market risk. The higher the market risk of a stock, the higher also the expected return. This is because human being demand a higher return for high risk stock. However if human risk preference is fluctuating, then beta is not adequate to measure a stock's risk. A stock might have a low beta but if certain situation renders stock holders reluctant to take risk, that stock will be perceived as highly risky with high expected return. In the contrary, a high beta stock might be perceived as low risk if situation renders stock holder eager to take risk. The stock will then has low expected return.

The theory that first describes human as always risk averse is Expected Utility Theory (EUT). EUT describes the relation between value and the utility that human being derived from it. This theory is widely used to describe how human will act in certain situation (Frisch and Clemen, 1994; Schoemaker, 1982; Starmer, 2000). In EUT, relation between value and utility is described as a concave shaped utility function (Neumann and Morgenstern, 1953). The concave shaped utility function causes diminishing marginal utility of wealth, where increasing value results in continuously smaller utility as the value getting higher (Rabin, 2000). Diminishing marginal utility of wealth is the cause of human risk aversion. It is not worth it to gamble higher value (small gain in utility) against lower value (bigger loss in utility) unless the increase of value is much bigger than the possible value reduction (Rabin, 2000; Bombardini dan Trebbi, 2012).

One view from psychology is that an individual risk preference is innate and ingrained in early life. As such, it is a personal trait unique to each individual and largely constant (schoemaker, 1993). Psychologists coin the term Intrinsic Risk Attitude (IRA) to describe individual's innate risk preference. Other than IRA, an individual risk taking behavior is also affected by his/her level of optimism and overconfidence (Nosic and Weber, 2007). Someone with higher level of optimism and overconfidence will more likely to take higher 
risk. Weber and Milliman (1997) disagree that risk taking behavior depends only on internal innate factors. Although risk preference was found as a stable it is discovered that an individual's risk perception affect the risk taking behavior. Risk perception is how an individual perceived whether a situation is high or low risk. An individual with low risk preference might be willing to take risky decision if he/she perceived the situation as low risk. On the other hand, someone with high risk preference might not be willing to take risky decision if he/she perceived the situation as high risk. Nosic and Weber (2007) shows that an individual risk taking behavior is determined by all those factors namely innate risk preference, optimism, overconfidence, and risk perception.

Other factors that can affect risk taking behavior is the current situation of an individual. Whether an individual is currently in positive or negative situation can affect his or her risk preference. There are two models that describes how positive or negative situation affect an individual's risk taking behavior, Reflection Effect in Prospect Theory and House Money Effect. Reflection Effect in Prospect Theory predicts that an individual in positive situation will be risk averse, while an individual in negative situation will be risk seeking (Kahneman and Tversky, 1979). The result has been corroborated many times (For example Camerer, 1998; Kühberger et al., 1999; Baucells and Vilsasis, 2010; etc). Reflection Effect has also been used to explain various economic phenomena successfully. Grinblat and Han (2005) explain Return Momentum phenomenon in stock market using Reflection Effect in Prospect Theory. Camerer et al. (1997) used reflection effect in Prospect Theory to explain the odd behavior of New York taxi drivers that work shorter time during peak hours but longer time during non-peak hours. Reflection Effect is caused by the shape of utility function as described by prospect Theory. According to Prospect Theory, the relation between value and utility is concave in positive situation, but convex in negative situation. Concave relation in positive situation causes any increase in value will result in smaller utility compared to decreased utility resulting from decrease in same amount of value. Thus in positive situation, people will be reluctant to take risk. In negative situation, the relation between value and utility is convex. In this case, increase of value will result in higher utility compared to utility decrease due to reduction of the same amount of value. The result is people will be willing to take risk.

Different outcome on how situation affects an individual's risk taking behavior is predicted by House Money Effect. House Money Effect is first reported by Thaler and Johnson (1990), describing the relation between positive and negative situation to an individual's risk taking behavior. In contrary to Reflection Effect, House Money Effect predicts that in positive situation people will be more willing to take risk compared to negative situation. In House Money Effect, positive situation creates a slack that can be risked away and thus people will be more willing to take risk. In negative situation, people is already in loss situation and thus is unwilling to take any more risk.

\section{Literature Review}

\section{Risk Taking Behavior under Prospect Theory}

Prospect Theory is a further development of Expected Utility Theory. In Expected Utility Theory, the way human being derive utility from value is described by Von Neumann - Morgenstern Utility Function as showed in Figure 1.

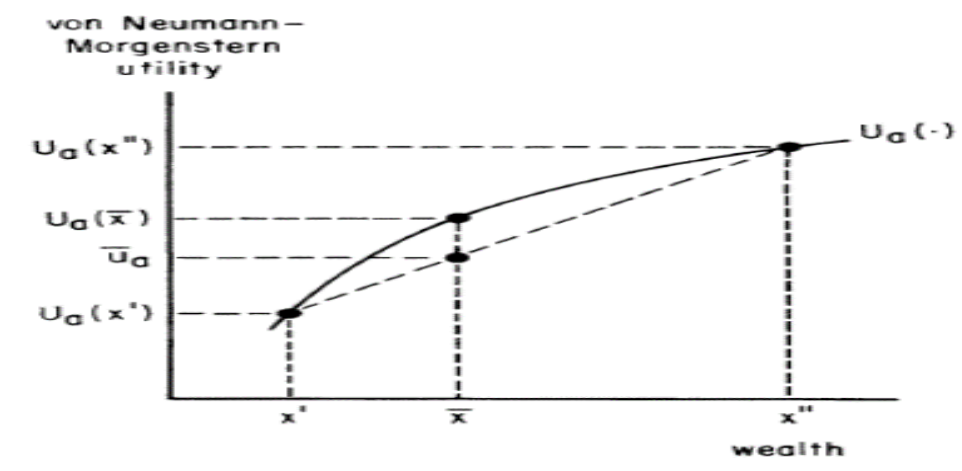

Figure 1: Von Neumann - Morgenstern Utility Function

Source: Machina (1987) 
The concave shaped utility function means as value (or wealth) increase, it generates smaller and smaller utility. This phenomenon is known as diminishing marginal utility of wealth, and creating risk averse behavior in all human being in all situation.

In Prospect Theory utility is not derived from value but from change of value (Kahneman and Tversky, 1979). As change of value can be either positive or negative, the utility function is separated between positive and negative value change. The utility function in Prospect Theory is described in Figure 2

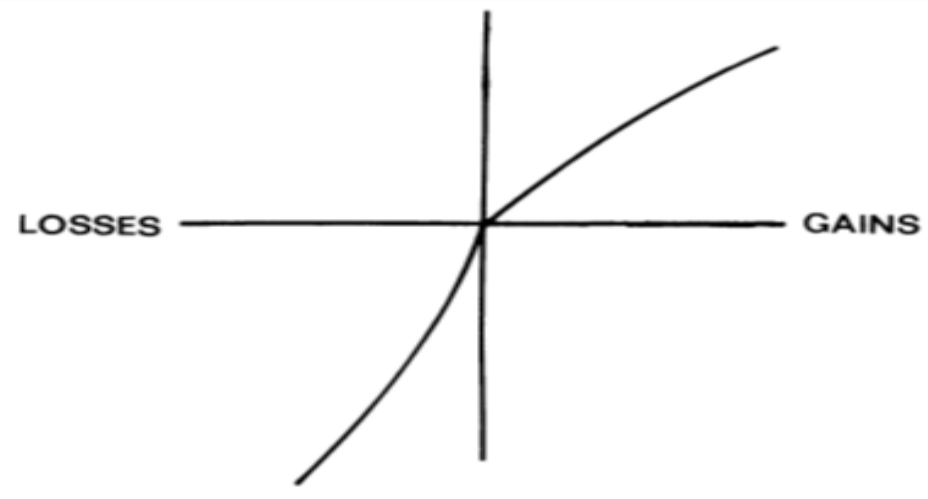

Figure 2: Utility Function in Prospect Theory

\section{Source: Kahneman and Tversky (1979)}

Figure 2 shows utility function in Prospect Theory. As in Expected Utility Theory, the y-axis is utility. However, in this model the $\mathrm{x}$-axis is change of value. There are two areas, gains (positive change in value) and loss (negative change in value). In gain area the relation between value and utility is concave, thus people will behave in risk averse manner. In loss area the relation is convex. In this case, people will behave in risk seeking manner. This phenomenon is known as Reflection Effect, where people is risk averse in positive situation but risk seeking in negative situation.

\section{Risk Taking Behavior under House Money Effect}

House Money Effect builds on the Prospect Theory with some vital differences. In House Money Effect loss after initial gain is integrated into each other so loss after an initial gain is considered merely a reduction of gain in human mind (Thaler and Johnson, 1990). Reduction of gain is less painful compared to outright loss. Thus an individual will be more willing to take risk in a positive situation. After an initial loss, additional loss will be integrated to it and considered a deepening of loss instead of a new loss. Deepening of an already materialized initial loss is more painful compared to a new loss. Thus after an initial loss and individual will be less likely to take a risky behavior.

\section{Hypothesis}

Both Reflection Effect and House Money Effect agree that an individual risk taking behavior is not fix, and affected by situation. They differ on how the situation will affect risk taking behavior. Reflection Effect predicts that positive situation will make an individual to be risk averse, while negative situation will make an individual risk seeking. In contrary, House Money Effect predicts that positive situation will make an individual risk seeking while negative situation will make an individual risk averse. The purpose of this paper is to test which model better predicts human risk taking behavior.

To determine whether Reflection Effect or House Money Effect is more accurate, risk taking behavior of company management under different situation is examined. In particular, it will be examined whether company management will take more or less risky decision in positive situation and in negative situation. More risky decision in positive situation and less risky decision in negative situation will support House Money Effect. Less risky decision in positive situation and more risky decision in negative situation will support Reflection Effect.

H1a: Risk taking behavior is more prevalent in positive situation compared to negative situation

$\mathrm{H} 1 \mathrm{~b}$ : Risk taking behavior is less prevalent in positive situation compared to negative situation 


\section{Method}

Each year companies in the sample are divided into companies with positive and negative situation. Positive situation is defined as companies with current year ROA higher compared to previous year ROA. Negative situation is defined as companies with current year ROA. Risk taking behavior is then calculated for each group to see which group will take more or less risk. Risk taking behavior of those two groups are then compared every year using independent student t-test. Risk taking behavior is measured using change of Debt level compared to the previous year. Debt level is calculated as Long Term Debt divided by Book Value of Equity.

The use of ROA to determine company situation is in accord to for example Cyert and March (1963), Miller and Leiblein (1996), and Bromiley (1991) that see all companies aspire to have higher profitability. Long Term Debt are used to measure risk taking behavior as it reflect certain level of uncertainty in the future (Hoskisson et al., 2017). Long Term Debt can result in bankruptcy risk in the future if future cash flow is lower than expected and thus give problem to service the interest expense. Long Term Debt are common proxies used to measure risk taking behavior. See for example Palmer and Wiseman (1999), Low (2009), Coles, Daniel, and Naveen (2006), Devers et al. (2008).

Sample used in this research is stocks from Indonesian Stock Exchange that are included in KOMPAS100 index. Sampling period is 2009 to 2016. KOMPAS100 index is an index consists of 100 most liquid stocks with good fundamental and high market capitalization from Indonesian Stock Exchange. Only stocks that stay in the index for at least 2 years are used. This is to ensure that only stocks with high liquidity and good fundamental are used as sample. Stocks from financial sector are excluded from sample as financial sector has distinct capital structure compared to other type of industry. KOMPAS100 stocks are re-arranged every January and July. For this research stocks from January period are used in a particular year.

\section{Result and Discussion}

Result of the calculation is as follow

Table 1: Difference in change of Debt level between companies in negative and positive situation

\begin{tabular}{|c|c|c|c|c|c|c|c|c|}
\hline & \multicolumn{3}{|c|}{ Companies in negative situation } & \multicolumn{3}{|c|}{ Companies in positive situation } & \multirow{2}{*}{$\begin{array}{l}\text { Difference in } \\
\Delta \text { Debt level }\end{array}$} & \multirow[b]{2}{*}{ Sig } \\
\hline & $\mathbf{N}$ & $\Delta$ Debt Level & STD & $\mathbf{N}$ & $\Delta$ Debt Level & STD & & \\
\hline 2009 & 21 & 0.177 & 0.58 & 36 & -0.114 & 0.42 & 0.291 & $0.035^{*}$ \\
\hline 2010 & 20 & -0.119 & 0.28 & 50 & -0.772 & 0.57 & 0.653 & 0.758 \\
\hline 2011 & 34 & 0.136 & 0.21 & 35 & -0.076 & 0.19 & 0.212 & $0.068^{* *}$ \\
\hline 2012 & 35 & 0.156 & 0.23 & 30 & 0.014 & 0.20 & 0.142 & $0.01 *$ \\
\hline 2013 & 54 & 0.095 & 0.20 & 21 & -0.013 & 0.24 & 0.108 & $0.053^{* *}$ \\
\hline 2014 & 42 & 0.087 & 0.21 & 28 & -0.002 & 0.13 & 0.089 & $0.05^{*}$ \\
\hline 2015 & 58 & 0.056 & 0.19 & 15 & -0.041 & 0.21 & 0.097 & $0.091^{* *}$ \\
\hline 2016 & 31 & 0.079 & 0.22 & 41 & -0.098 & 0.22 & 0.177 & $0.001 *$ \\
\hline
\end{tabular}

* Significant in $95 \%$ level

\section{** Significant in $90 \%$ level}

Table 1 shows the change in debt level for companies in negative and positive situation every year. Positive value means increase of debt level, and thus indicates risk taking behavior. Negative value means decrease of debt level, and thus indicates risk avoidance behavior. In every year except in 2010, companies in negative situation increase their debt level, indicating that they are taking more risk. In contrast, in every year except 2012 companies in positive situation decrease their debt level indicating they are reducing their level of risk. Comparison of debt level change between companies in negative and in positive situation shows that in every year except 2010 the difference is significant either in $95 \%$ or $90 \%$ confidence level.

The results strongly suggest that:

1. There is difference in risk taking behavior between companies in negative and in positive situation

2. Companies in negative situation tend to increase risk level

3. Companies in positive situation tend to decrease risk level 
The result is then supportive to Reflection Effect in Prospect Theory which describe human being is risk averse in positive situation but risk seeking in negative situation. The result does not support House Money Effect which describes human being as tend to take more risk in positive situation.

\section{Conclusion and Recommendation}

Assuming that change of debt level is an appropriate indicator of company management risk taking behavior, the result supports the notion that situation affects human risk taking behavior. More exactly, negative situation increase risk taking behavior while positive situation decrease it. The result is as expected according to Reflection Effect in Prospect Theory. The follow up research can use different indicators for both situation and risk taking behavior. Positive/negative situation can be determined using change of ROE or change of stock price. Other indicators that can be used to determine risk taking behavior are change of Capital Expenditure level or change of Research and Development expense.

\section{References}

[1.] Baucells, M., \& Villasís, A. (2010). Stability of risk preferences and the reflection effect of prospect theory. Theory and Decision, 68(1-2), 193-211.

[2.] Bombardini, M., \& Trebbi, F. (2012). Risk aversion and expected utility theory: an experiment with large and small stakes. Journal of the European Economic Association, 10(6), 1348-1399.

[3.] Bromiley, P. (1991). Testing a causal model of corporate risk taking and performance. Academy of Management journal, 34(1), 37-59.

[4.] Camerer, C., Babcock, L., Loewenstein, G., \& Thaler, R. (1997). Labor supply of New York City cabdrivers: One day at a time. The Quarterly Journal of Economics, 407-441.

[5.] Camerer, C. F. (1998). Prospect theory in the wild: Evidence from the field.

[6.] Coles, J. L., Daniel, N. D., \& Naveen, L. (2006). Managerial incentives and risk-taking. Journal of financial Economics, 79(2), 431-468.

[7.] Cyert, R. M., \& March, J. G. (1963). A behavioral theory of the firm. Englewood Cliffs, NJ, 2.

[8.] Devers, C. E., McNamara, G., Wiseman, R. M., \& Arrfelt, M. (2008). Moving closer to the action: Examining compensation design effects on firm risk. Organization Science, 19(4), 548-566.

[9.] Frisch, D., \& Clemen, R. T. (1994). Beyond expected utility: rethinking behavioral decision research. Psychological bulletin, 116(1), 46.

[10.] Grinblatt, M., \& Han, B. (2005). Prospect theory, mental accounting, and momentum. Journal of financial economics, 78(2), 311-339.

[11.] Hoskisson, R. E., Chirico, F., Zyung, J., \& Gambeta, E. (2017). Managerial Risk Taking: A Multi theoretical Review and Future Research Agenda. Journal of Management, 43(1), 137-169.

[12.] Kahneman, D., \& Tversky, A. (1979). Prospect theory: An analysis of decision under risk. Econometrica: Journal of the econometric society, 263-291.

[13.] Kühberger, A., Schulte-Mecklenbeck, M., \& Perner, J. (1999). The effects of framing, reflection, probability, and payoff on risk preference in choice tasks. Organizational behavior and human decision processes, 78(3), 204-231.

[14.] Low, A. (2009). Managerial risk-taking behavior and equity-based compensation. Journal of Financial Economics, 92(3), 470-490.

[15.] Machina, M. J. (1987). Choice under uncertainty: Problems solved and unsolved. Journal of Economic Perspectives, 1(1), 121-154.

[16.] Miller, K. D., \& Leiblein, M. J. (1996). Corporate risk-return relations: Returns variability versus downside risk. Academy of Management Journal, 39(1), 91-122.

[17.] Neumann, J., \& Morgenstern, O. (1953). Theory of Games and Economic Behavior: 3d Ed. Princeton University Press.

[18.] Nosic, A., \& Weber, M. (2007). Determinants of risk taking behavior: the role of risk attitudes, risk perceptions and beliefs.

[19.] Palmer, T. B., \& Wiseman, R. M. (1999). Decoupling risk taking from income stream uncertainty: A holistic model of risk. Strategic Management Journal, 20(11), 1037-1062.

[20.] Rabin, M. (2000). Risk aversion and expected-utility theory: A calibration theorem. Econometrica, 68(5), 1281-1292

[21.] Schoemaker, P. J. (1982). The expected utility model: Its variants, purposes, evidence and limitations. Journal of economic literature, 529-563. 
[22.] Schoemaker, P. J. (1993). Determinants of risk-taking: Behavioral and economic views. Journal of Risk and Uncertainty, 6(1), 49-73.

[23.] Starmer, C. (2000). Developments in non-expected utility theory: The hunt for a descriptive theory of choice under risk. Journal of economic literature, 38(2), 332-382.

[24.] Thaler, R. H., \& Johnson, E. J. (1990). Gambling with the house money and trying to break even: The effects of prior outcomes on risky choice. Management science, 36(6), 643-660.

[25.] Weber, E. U., \& Milliman, R. A. (1997). Perceived risk attitudes: Relating risk perception to risky choice. Management science, 43(2), 123-144. 